Vol. 1 No. 2 September 2021, p-2797-5592 | e-2797-5606

\title{
UPAYA PENINGKATAN PROFESIONALISME GURU MELALUI SUPERVISI AKADEMIK DI SMP NEGERI 5 LHOKSEUMAWE
}

\author{
SRI ARYATI \\ SMP Negeri 5 Lhokseumawe \\ e-mail: sriaryati170@yahoo.com
}

\begin{abstract}
ABSTRAK
Tujuan penelitian ini adalah Untuk meningkatkan profesionalisme guru dalam melaksanakan tugas pokok dan fungsinya sebagai pendidik. Melalui pengelolaan administrasi sekolah melalui supervise akademik dan manajerial pada setiap unit kegiatan. Subjek penelitian tindakan sekolah ini adalah Guru Sekolah SMP Negeri 5 Lhokseumawe, yang berjumlah 23 orang guru, dengan rincian 20 orang guru perempuan, dan 3 orang guru laki-laki. Penelitian tindakan sekolah ini dilaksanakan pada tahun pelajaran 2019/2020, yang dilaksanakan dalam kurun waktu 2 bulan yaitu dari bulan Agustus sampai dengan Oktober 2019 pada semester ganjil. Metodologi penelitian ini adalah penelitian tindakan sekolah yang terdiri dari dua siklus, dan setiap siklus terdiri dari satu kali pertemuan. Pada setiap siklus terdiri dari perencanaan, pelaksanaan, observasi, dan refleksi. Prosedur penelitian terdiri dari pra penelitian, perencanaan siklus I, pelaksanaan tindakan siklus I, pengamatan siklus I, refleksi siklus I, perencanaan siklus II, pelaksanaan tindakan siklus II, pengamatan siklus II, dan refleksi siklus II. Teknik pengumpulan data yaitu dengan mengumpulkan instrumen yang dilaksanakan pada setiap akhir penelitian pada setiap siklus dengan menggunakan instrumen. Data dianalisis dengan cara statistic persentase. Hasil penelitian menunjukkan bahwa terjadi peningkatan pada kondisi awal penelitian dengan jumlah guru 23 Orang, guru baik sekali berjumlah 10 orang yaitu 43,47\%, guru baik berjumlah 11 orang yaitu 47,82\%, dan guru cukup 2 orang yaitu $8,71 \%$. Pada saat pelaksanaan supervisi admistrasi pembelajaran didapatkan hasil penilain jumlah guru baik sekali berjumlah 16 Orang yaitu 69,56\%, guru baik berjumlah 6 Orang yaitu 26,08\% dan guru cukup 1 orang yaitu 4,36\%. Oleh karenanya, penerapan supervisi akademik dapat meningkatkan kemampuan profesionalisme guru SMP Negeri 5 Lhokseumawe tahun pelajaran 2019/2020.
\end{abstract}

Kata Kunci : Profesionalisme guru, supervisi akademik, meningkatkan profesional guru

\section{PENDAHULUAN}

Secara bahasa, kata supervisi berasal dari Bahasa Inggris supervision yang berarti pengawasan (Tim, $2001 \mathrm{a}$ : 84). Kata ini berasal dari dua kata super dan vision yang berarti melihat dengan teliti pekerjaan secara keseluruhan (Thaib, 2005 : 2). Sedang menurut istilah, pengertian supervisi mula-mula dimaknai secara tradisional yaitu sebagai suatu pekerjaan menginspeksi, memeriksa, dan mengawasi dengan mencari-cari kesalahan melalui cara memata-matai dalam rangka perbaikan pekerjaan yang telah diberikan. Kemudian berkembang pemahaman supervisi yang bersifat ilmiah dengan ciri-ciri sebagai berikut (Sahertian, 2000 : 16-17) :

1. Sistematis, artinya supervisi dilakukan secara teratur, berencana, dan kontinyu.

2. Obyektif, artinya supervisi dilakukan berdasarkan data hasil observasi yang dilakukan sebelumnya.

3. Menggunakan instrumen yang dapat memberikan informasi sebagai umpan balik untuk dapat melakukan langkah tindak lanjut menuju perbaikan di masa yang akan datang.

Secara etimologi kata supervisi berasal dari kata super yang artinya mempunyai kelebihan tertentu seperti kelebihan dalam pangkat, jabatan dan kualias, sedang visi artinya melihat atau mengawasi Karena itu supervisi dapat diartikan sebagai kegiatan pengawasan yang dilakukan oleh seorang pejabat terhadap bawahannya untuk melakukan tugas dan kewajibannya dengan baik sesuai dengan tugas yang telah digariskan (Burhanuddin, 2005: 99). 
Vol. 1 No. 2 September 2021, p-2797-5592 | e-2797-5606

Undang-undang No 20 Tahun 2003 tentang Sistem Pendidikan Nasional menyatakan bahwa pendidikan adalah usaha sadar terencana untuk mewujudkan suasana belajar dan proses pembelajaran agar peserta didik secara aktif mengembangkan potensi dirinya untuk memiliki kekuatan spiritual keagamaan, pengendalian diri, kepribadian, kecerdasan, akhlak mulia, serta keterampilan yang diperlukan dirinya, masyarakat, bangsa dan Negara. Tujuan pendidikan dan pengajaran diartikan sebagai suatu bentuk usaha untuk memberikan rumusan hasil yang diharapkan dari siswa/siswi sebagai subjek belajar, sehingga memberi arah kemana proses belajar mengajar itu harus dibawa dan dilaksanakan.

Permendiknas Nomor 13 Tahun 2007 menyatakan bahwa seorang Kepala Sekolah harus menguasai Standar Kompetensi Kepala Sekolah yang terdiri atas : kompetensi kepribadian, kompetensi manajerial, kompetensi supervisi Akademik, kompetensi kewirausahaan dan kompetensi sosial. Penjabaran kompetensi supervisi pada intinya adalah supervisi akademis dimana langkah-langkah yang dilakukan adalah merencanakan program supervisi akademik dalam rangka peningkatan profesionalisme guru, melaksanakan supervisi akademik terhadap guru dengan menggunakan pendekatan dan teknik supervisi yang tepat serta menindaklanjuti hasil supervisi akademik terhadap guru dalam rangka peningkatan profesionalismenya salah satu tugas kepala sekolah adalah melaksanakan supervisi akademik pada para pendidik yang berada dilingkungannya. Setiap kepala sekolah harus memiliki dan menguasai konsep supervisi akademik secara efektif diperlukan keterampilan konseptual pengertian, tujuan, fungsi, prinsip-prinsip dan dimensi-dimensi substansi supervisi akademik lainnya. Penjabaran kompetensi supervisi pada intinya adalah supervisi akademis dimana langkah-langkah yang dilakukan adalah merencanakan program supervisi akademik dalam rangka peningkatan profesionalisme guru, melaksanakan supervisi akademik terhadap guru dengan menggunakan pendekatan dan teknik supervisi yang tepat serta menindaklanjuti hasil supervisi akademik terhadap guru dalam rangka peningkatan profesionalismenya.

Mencermati hasil analisis Program Supervisi Tahun Pelajaran 2019/2020 pada SMP Negeri 5 Lhokseumawe secara umum ditemukan beberapa kelemahan yang perlu diperbaiki bagi peningkatan kualitas pembelajaran sekaligus peningkatan profesionalisme guru, seperti : pengembangan indikator dan materi pembelajaran, penggunaan metode pembelajaran yang belum variatif, lemahnya penguasaan guru dalam model-model pembelajaran aktif, dan sebagainya.

Supervisi akademik yang dilakukan kepala sekolah anatar lain adalah sebagai berikut : (1) Memahami konsep, prinsip, teori dasar, karateristik, dan kecenderungan perkembangan pembelajaran kreatif, inovatif, pemecahan masalah, berpikir kritis dan naluri kewirausahaaan. (2) Membimbing guru dalam menyusun silabus tiap bidang pengembangan di sekolah/madrasah atau mata pelajaran disekolah/madrasah berlandaskan standar isi, kompetensi inti dan kompetensi dasar, dan prinsip-prinsip pengembangan Kurikulum 2013. (3) Membimbing guru dalam memilih dan menggunakan strategi/metode/teknik pembelajaran/bimbingan yang dapat mengembangkan berbagai potensi siswa. (4) Membimbing guru dalam melaksanakan kegiatan pembelajaran / bimbingan (dikelas, laboratorium, dan / atau di lapangan) untuk mengembangkan potensi siswa. (5) Membimbing guru dalam mengelola, merawat, mengembangkan dan menggunakan media pendidikan dan fasilitas pembelajaran. (6) Memotivasi guru untuk mmemanfaatkan teknologi informasi untuk pembelajaran. Kompetensi supervisi akademik intinya adalah membina guru dalam meningkatkan mutu proses pembelajaran. Sasaran supervisi akademik intinya membina guru dalam meningkatkan mutu proses pembelajaran, yang terdiri dari materi pokok dalam proses pembalajaran, penyusunan silabus dan RPP, pemilihan strategis / metode / teknik pembelajaran, penggunaan media dan teknologi informasi dalam pembelajaran, menilai proses dan hasil pembelajaran serta penelitian tindakan kelas. Mencermati hasil analisis program supervisi Tahun 2019/2020 pada SMP Negeri 5 Lhokseumawe, secara umum ditemukan beberapa kelemahan- 
kelemahan yang perlu diperbaiki bagi peningkatan kualitas pembelajaran dan peningkatan profesionalisme guru.

\section{METODE PENELITIAN}

Penelitian ini adalah penelitian tindakan sekolah (PTS), PTS adalah penelitian yang dilakukan oleh kepala sekolah di sekolah yang dibina dan dipimpin dengan penekanan pada penyempurnaan atau peningkatan proses dan praktis pembelajaran.

PTS dilaksanakan dengan strategi siklus yang berangkat dari identifikasi masalah yang dihadapi oleh guru, penyusunan rencana tindakan, pelaksanaan tindakan, observasi tindakan, dan refleksi. Rangkaian kegiatan berurutan mulai dari rencana tindakan sampai dengan refleksi disebut satu siklus penelitian. Setiap siklus terdiri dari empat tahap, yakni: Penelitian ini diakhiri pada siklus kedua. Secara jelas, langkah-langkah (1) perencanaan tindakan, (2) pelaksanaan tindakan, (3) observasi dan interprestasi, dan (4) analisis dan refleksi

\section{HASIL DAN PEMBAHASAN}

\section{A. Kondisi Awal Penelitian}

Standar penilaian termasuk bagian badan standar nasional pendidikan yang harus dilaksanakan oleh setiap lembaga pendidikan yang bertaraf formal. Dimana BSNP terdiri dari 8 standar, yaitu standar Isi, Proses, Kelulusan, Kependidikan, Saspras, Pengelolaan, Pembiayaan dan penilaian. Untuk mewujutkan proses penilaian yang baik, harus mempunyai perangkat-perangkat penilaian. Oleh karena itu kami mencoba melakukanan supervisi terhadap administrasi penilaian dalam pembelajaran. Dan kami telah melakukan supervisi tersebut kepada 23 orang guru.

Keberhasilan seseorang guru dalam mengajar sangat ditentukan oleh persiapan mengajar yang matang. Admistrasi merupakan hal yang sangat urgen dalam menyukseskan seorang guru, seperti kalender pendidikan, program tahunan, program semester, silabus, penetapan KKM, RPP, jadwal tatap muka, buku absen siswa, daftar nilai dan agenda harian, bahan-bahan yang sangat diperlukan guru dalam melaksanakan tugas dalam pembelajaran. Dalam semester ganjil tahun 2019 kami telah melakukan supervisi kepada 23 orang guru. Berdasarkan hasil supervisi awal yang kami lakukan dapat dilihat pada tabel berikut:

Tabel 1. Kondisi Awal Penelitian Administrasi Pembelajaran

\begin{tabular}{|c|c|c|c|c|c|c|c|c|c|c|c|c|c|c|c|}
\hline \multicolumn{16}{|c|}{ Penilaian Administrasi Pembelajaran } \\
\hline \multirow[t]{2}{*}{ No } & \multirow[t]{2}{*}{ Nama Guru } & \multicolumn{12}{|c|}{$\begin{array}{c}\text { Instrumen } \\
\end{array}$} & \multirow[t]{2}{*}{ Skor } & \multirow{2}{*}{ Nilai } \\
\hline & & 1 & 2 & 3 & 4 & 5 & 6 & 7 & 8 & 9 & 10 & 11 & 12 & & \\
\hline 1 & Sri Mulyani, S.Pd & 3 & 3 & 4 & 3 & 4 & 2 & 4 & 2 & 4 & 3 & 4 & 4 & 40 & 83.33 \\
\hline 2 & Nazar Enannur. & 3 & 3 & 4 & 2 & 4 & 2 & 4 & 3 & 4 & 2 & 4 & 4 & 39 & 81.25 \\
\hline 3 & Lisa Santi, S.Pd & 4 & 3 & 4 & 3 & 3 & 2 & 2 & 2 & 3 & 3 & 4 & 4 & 37 & 77.08 \\
\hline 4 & Nora Martini, & 4 & 4 & 4 & 4 & 4 & 3 & 3 & 3 & 3 & 3 & 4 & 4 & 43 & 89.58 \\
\hline 5 & Nazaruddin, S.Pd & 2 & 2 & 2 & 2 & 2 & 2 & 2 & 4 & 2 & 4 & 4 & 4 & 32 & 66.67 \\
\hline 6 & Andriani, S.Pd.I & 4 & 4 & 4 & 3 & 4 & 3 & 3 & 4 & 4 & 4 & 4 & 4 & 45 & 93.75 \\
\hline 7 & $\begin{array}{l}\text { Cut Rahmi } \\
\text { Zainuddin }\end{array}$ & 3 & 3 & 3 & 2 & 3 & 3 & 2 & 3 & 3 & 3 & 4 & 4 & 36 & 75.00 \\
\hline 8 & Murdani, Ss & 4 & 4 & 3 & 4 & 4 & 3 & 3 & 3 & 4 & 4 & 3 & 3 & 42 & 87.50 \\
\hline 9 & Widya Nanda, & 4 & 4 & 3 & 3 & 4 & 3 & 3 & 4 & 3 & 3 & 3 & 4 & 41 & 85.42 \\
\hline 10 & Suryani, S.Sos & 3 & 3 & 3 & 4 & 3 & 3 & 2 & 3 & 3 & 3 & $\frac{3}{4}$ & 4 & 38 & 79.17 \\
\hline 11 & Henni Sujanna, & 4 & 4 & 3 & 4 & 4 & 3 & 3 & 3 & 3 & 4 & 4 & 4 & 43 & 89.58 \\
\hline 12 & Nurlailawati, S.Pd & 4 & 4 & 4 & 4 & 4 & 3 & 3 & 3 & 4 & 4 & 3 & 4 & 44 & 91.67 \\
\hline 13 & Eliyanur, S.Pd & 4 & 4 & 3 & 4 & 4 & 3 & 3 & 3 & 4 & 3 & 4 & 4 & 43 & 89.58 \\
\hline 14 & Seri Rahayu, S.Pd & 4 & 3 & 3 & 3 & 2 & 3 & 0 & 0 & 2 & 3 & 3 & 3 & 29 & 60.42 \\
\hline 15 & Yusnidar Ramli. & 4 & 4 & 3 & 4 & 4 & 3 & 3 & 3 & 4 & 4 & 4 & 4 & 44 & 91.67 \\
\hline 16 & Zahriana, S.Pd & 4 & 4 & 3 & 4 & 4 & 3 & 2 & 3 & 3 & 3 & 4 & 4 & 41 & 85.42 \\
\hline
\end{tabular}


Vol. 1 No. 2 September 2021, p-2797-5592 | e-2797-5606

\begin{tabular}{|l|l|l|l|l|l|l|l|l|l|l|l|l|l|l|l|}
\hline 17 & Yunda Nafsiah. & 4 & 3 & 4 & 4 & 4 & 3 & 3 & 3 & 2 & 3 & 4 & 4 & 41 & 85.42 \\
\hline 18 & Erna Wati, S.Pd & 4 & 4 & 4 & 3 & 4 & 3 & 0 & 3 & 3 & 4 & 3 & 4 & 39 & 81.25 \\
\hline 19 & Mutia Nurdin, & 4 & 4 & 4 & 4 & 4 & 3 & 4 & 3 & 4 & 3 & 3 & 4 & 44 & 91.67 \\
\hline 20 & Raimahwati, S.Pd & 4 & 4 & 4 & 4 & 4 & 3 & 4 & 3 & 4 & 4 & 3 & 3 & 44 & 91.67 \\
\hline 21 & Nurakmal, S.Pd & 4 & 4 & 4 & 4 & 4 & 4 & 3 & 3 & 3 & 3 & 3 & 3 & 42 & 87.50 \\
\hline \multicolumn{2}{|c|}{ Sko } & 78 & 75 & 73 & 72 & 77 & 60 & 56 & 61 & 69 & 70 & 76 & 80 & & \\
\hline Ketercapaian Dalam & 93 & 89 & 87 & 86 & 92 & 71 & 67 & 73 & 82 & 83 & 90 & 95 & & \\
\hline
\end{tabular}

Dari tabel di atas, ada 2 orang guru yang belum sempurna melengkapi ADM pembelajaran, yaitu Nazaruddin, S.Pd 66,67 dan Seri Rahayu, S.Pd 60,42, maka kami melakukan tindak lanjut terhadap guru tersebut memanggil dan membina untuk melengkapi bahan administrasi pembelajarannya sesuai dengan bidang studi yang di ampu.

\section{B. Hasil Penelitian Pelaksanaan Administrasi Pembelajaran}

Tabel 2. Hasil Penelitian Pelaksanaan Administrasi Pembelajaran

\begin{tabular}{|c|c|c|c|c|c|c|c|c|c|c|c|c|c|c|c|}
\hline \multirow[b]{2}{*}{ No } & \multirow[b]{2}{*}{ Nama Guru } & \multicolumn{12}{|c|}{ Perangkat } & \multirow[b]{2}{*}{ Skor } & \multirow{2}{*}{ Nilai } \\
\hline & & 1 & 2 & 3 & 4 & 5 & 6 & 7 & 8 & 9 & 10 & 11 & 12 & & \\
\hline 1 & Sri Mulyani, S.Pd & 4 & 4 & 4 & 4 & 4 & 4 & 4 & 2 & 4 & 4 & 4 & 4 & 46 & 95,00 \\
\hline 2 & $\begin{array}{l}\text { Nazar } \\
\text { Epannur, }\end{array}$ & 4 & 4 & 4 & 4 & 4 & 4 & 4 & 2 & 4 & 2 & 4 & 4 & 44 & 91,00 \\
\hline 3 & Lisa Santi, S.Pd & 4 & 3 & 4 & 3 & 3 & 3 & 3 & 3 & 3 & 3 & 4 & 4 & 40 & 83,00 \\
\hline 4 & Nora Martini, & 4 & 4 & 4 & 4 & 4 & 4 & 4 & 3 & 3 & 4 & 4 & 4 & 46 & 95,80 \\
\hline 5 & Nazaruddin, S.Pd & 2 & 2 & 2 & 2 & 2 & 4 & 4 & 4 & 2 & 4 & 4 & 4 & 36 & 75,00 \\
\hline 6 & Andriani, S.Pd.I & 4 & 4 & 4 & 4 & 4 & 4 & 4 & 4 & 4 & 4 & 4 & 4 & 48 & 100,00 \\
\hline 7 & $\begin{array}{l}\text { Cut Rahmi } \\
\text { Zainuddin, }\end{array}$ & 4 & 2 & 2 & 2 & 2 & 2 & 2 & 2 & 2 & 2 & 4 & 4 & 39 & 81,00 \\
\hline 8 & Murdani, Ss & 4 & 4 & 4 & 4 & 4 & 4 & 3 & 3 & 4 & 4 & 3 & 3 & 44 & 91,60 \\
\hline 9 & Widva Nanda, & 4 & 4 & 4 & 3 & 4 & 4 & 3 & 4 & 3 & 3 & 3 & 4 & 43 & 89,00 \\
\hline 10 & Survani, S.Sos & 4 & 3 & 3 & 3 & 3 & 3 & 3 & 3 & 3 & 3 & 4 & 4 & 39 & 82,00 \\
\hline 11 & Henni Sujanna, & 4 & 4 & 4 & 4 & 4 & 4 & 3 & 3 & 4 & 4 & 4 & 4 & 44 & 91,60 \\
\hline 12 & Nurlailawati, S.Pd & 4 & 4 & 4 & 4 & 4 & 4 & 4 & 3 & 4 & 4 & 3 & 4 & 46 & 95,83 \\
\hline 13 & Elivanur, S.Pd & 4 & 4 & 4 & 4 & 4 & 4 & 3 & 3 & 4 & 3 & 4 & 4 & 45 & 93,75 \\
\hline 14 & Seri Rahayu, S.Pd & 4 & 3 & 4 & 3 & 2 & 3 & 2 & 0 & 2 & 3 & 3 & 3 & 32 & 66,67 \\
\hline 15 & $\begin{array}{l}\text { Yusnidar } \\
\text { Ramli, S.Pd }\end{array}$ & 4 & 4 & 4 & 4 & 4 & 4 & 3 & 3 & 4 & 4 & 4 & 4 & 46 & 95,00 \\
\hline 16 & Zahriana, S.Pd & 4 & 4 & 4 & 4 & 4 & 4 & 2 & 3 & 3 & 3 & 4 & 4 & 40 & 83,00 \\
\hline 17 & $\begin{array}{l}\text { Yunda } \\
\text { Nafsiah, }\end{array}$ & 4 & 4 & 4 & 4 & 4 & 3 & 3 & 3 & 2 & 3 & 4 & 4 & 42 & 87,50 \\
\hline 18 & Erna Wati, S.Pd & 4 & 4 & 4 & 3 & 4 & 3 & 0 & 3 & 4 & 4 & 3 & 4 & 40 & 83,00 \\
\hline 19 & Mutia Nurdin, & 4 & 4 & 4 & 4 & 4 & 4 & 4 & 3 & 4 & 3 & 3 & 4 & 45 & 93,75 \\
\hline 20 & Raimahwati, S.Pd & 4 & 4 & 4 & 4 & 4 & 4 & 4 & 3 & 4 & 4 & 3 & 3 & 45 & 93,75 \\
\hline 21 & Nurakmal, S.Pd & 4 & 4 & 4 & 4 & 4 & 4 & 3 & 3 & 3 & 3 & 3 & 3 & 42 & 87,50 \\
\hline & Skor & 82 & 77 & 79 & 75 & 76 & 77 & 65 & 60 & 70 & 71 & 76 & 80 & & \\
\hline Ke & ercapaian Da & 98 & 92 & 94 & 89 & 90 & 92 & 77 & 71 & 83 & 85 & 90 & 95 & & \\
\hline
\end{tabular}

Dari tabel di atas masih ada 1 guru yang belum sempurna melengkapi administrasi pembelajaran, yaitu Seri Rahayu, S.Pd dengan nilai akhir 66,67 maka kami melakukan tindak lanjut terhadap guru tersebut memanggil dan membina untuk melengkapi bahan administrasi pembelajarannya, sesuai dengan bidang studi yang di ampu.

Dari tabel di atas terlihat bahwa kompetensi penyusunan administrasi penilain pembelajaran mengalami peningkatan. Pada kondisi awal penelitian dengan jumlah guru 23 Orang, 
guru baik sekali berjumlah 10 orang yaitu 43,47\%, guru baik berjumlah 11 orang yaitu 47,82\%, dan guru cukup 2 orang yaitu 8,71\%. Pada saat pelaksanaan supervisi admistrasi pembelajaran didapatkan hasil penilain jumlah guru baik sekali berjumlah 16 Orang yaitu 69,56\%, guru baik berjumlah 6 Orang yaitu 26,08\% dan guru cukup 1 orang yaitu 4,36\%.

Hal ini sesuai dengan pendapat yang disampaikan oleh Glickman (1981) menyatakan bahwa kegiatan supervisi akademik adalah untuk membantu guru mengembangkan kemampuan mencapai tujuan pembelajaran yang direncanakan bagi murid-muridnya. Dengan demikian tujuan yang paling pokok dalam supervisi pembelajaran bagaimana guru mencapai tujuan pembelajaran yang telah ditetapkan. Selain itu, supervisi pembelajaran bertujuan untuk meningkatkan pertumbuhan, pengembangan, interaksi, penyeleseian masalah dan sebuah komitmen untuk membangun kapasitas guru.

Hasil supervisi perlu ditindak lanjuti agar memberi dampak yang nyata untuk meningkatkan profesionalisme guru dan pegawai, dampak nyata ini diharapkan dan dirasakan oleh masyarakat maupun stakeholder. Tindak lanjut dilaksanakan kepada guru yang nilainya rendah di lakukan pembinaan, baik personal maupun kelompok. Sehingga guru tahu dimana kelemahan - kelemahan yang ada padanya.

Pada supervisi administrasi pembelajaran terdapat 2 orang guru yang nilainya masih rendah, maka kami melakukan tindak lanjut kepada guru tersebut berupa bimbingan secara individu, dengan harapan kekurangan-kekurangan yang ada pada saat ini dapat diperbaiki di masa mendatang. Adapun guru tersebut adalah Nazaruddin, S.Pd dan Seri Rahayu, S.Pd.

Pada supervisi pelaksanaan pembelajaran didapatkan 1 orang guru yang belum maksimal mendapatkan nilainya. Masih ada beberapa kendala yang hadapi pada saat melengkapi administrasi pembelajaran. Oleh karena ini, tindak lanjut yang kami lakukan adalah dengan memberikan movitasi berupa bimbingan pribadi dan belajar

dengan teman sejawat agar administrasi pembelajaran menjadi lebih baik dimasa mendatang. Adapun guru tersebut adalah Seri Rahayu, S.Pd.

Pada supervisi penilaian pembelajaran terdapat banyak sekali para guru yang belum melaksanakan metode atau cara penilaian yang sesuai. Pada supervisi penilaian ada 2 guru yang mendapatkan hasil yang kurang bagus. Oleh karena itu tidak lanjut yang kami lakukan adalah membuat pelatihan tentang cara memberikan penilaian yang benar didalam pembelajaran.

Turner (1970) mengatakan bahwa supervisi merupakan sebuah proses sosial dari stimulasi, pengasuhan, dan memprediksi pengembangan profesional guru dan pengawas sebagai penggerak utama dalam pengembangan kondisi pembelajaran secara optimum. Tujuan lainnya dari supervisi pembelajaran menurut beberapa ahli adalah untuk (1) menginteraksikan (2) meningkatkan kualitas belajar peserta didik (3) membangun kepercayaan (4) mengubah hasil pembelajaran dan mengembangkan kehidupan yang lebih baik.

Sejalan dengan pendapat diatas, permendiknas no 39 tahun 2009 menyebutkan bahwa ruang lingkup supervisi akademik meliputi : a) membina guru dalam merencanakan, melaksanakan dan menilia proses pembelajaran, b) memantau pelaksanaan standar isi, c) memantau pelaksanaan standar proses, d) memantau pelaksanaan standar kompetensi lulusan, e) memantau pelaksanaan standar tenaga pendidik dan kependidikan, dan f) memantau pelaksanaan standar penilain.

Peningkatan mutu guru yang berkualitas perlu dilakukan secara terprogram, terstruktur dan berkelanjutan melalui pembinaan profesional oleh kepala sekolah. Melalui supervisi akademik kepala sekolah mampu menampung berbagai masalah yang dihadapi oleh guru dalam proses pembelajaran untuk dapat menentukan cara-cara pemecahan masalah. Esensi supervisi akademik bukanlah menilian unjuk kerja guru dalam mengelola

proses pembelajaran, melainkan untuk membantu guru mengembangkan kemampuan profesionalismenya. 
Penilaian dalam mengelola proses pembelajaran sebagai suatu proses pemberian estimasi kualitas unjuk kerja guru dalam mengelola proses pembelajaran, merupakan bagian yang tak terpisahkan dari serangkaian kegiatan supervisi.

\section{KESIMPULAN}

Berdasarkan hasil penelitian dan pembahasan menunjukkan bahwa kompetensi penyusunan administrasi penilain pembelajaran mengalami peningkatan. Pada kondisi awal penelitian dengan jumlah guru 23 Orang, guru baik sekali berjumlah 10 orang yaitu 43,47\%, guru baik berjumlah 11 orang yaitu $47,82 \%$, dan guru cukup 2 orang yaitu $8,71 \%$. Pada saat pelaksanaan supervisi admistrasi pembelajaran didapatkan hasil penilain jumlah guru baik sekali berjumlah 16 Orang yaitu 69,56\%, guru baik berjumlah 6 Orang yaitu 26,08\% dan guru cukup 1 orang yaitu 4,36\%.

\section{DAFTAR PUSTAKA}

Arikunto, Suharsimi. (2006). Dasar-Dasar Supervisi. Jakarta Rineka Cipta.

Burhanuddin. (2005). Analisis Adminiostrasi Manajemen dan Kepemimpinan Pendidikan. Jakarta : Bumi Aksara.

Peraturan Pemerintah Republik Indonesia Nomor 13 tahun 2007.Tentang Standar Kepala Sekolah/Madrasah. Jakarta.

Peraturan Pemerintah Republik Indonesia Nomor 19 tahun 2005. Tentang Standar Nasional Pendidikan Nasional. Jakarta.

Peraturan Pemerintah Republik Indonesia Nomor 20 tahun 2003.Tentang Sistem Pendidikan Indonesia. Jakarta.

Fatah, Nanang. (2000). Landasan Manajemen Pendidikan. Bandung. Rosdakarya.

Gunawan, A. (2008). Administrasi Sekolah. Jakarta : Rineka Cipta.

Hasan, I. (2001). Analisis Tentang Inovasi dan Kinerja Pegawai Antar Unit Kerja. Universitas Syiah Kuala. Banda Aceh.

Mutallib, A. (2008). Program Kerja Kepala Sekolah Dalam Peningkatan Profesionalisme Guryu. Universitas Syiah Kuala. Banda Aceh

Ngalim Puwanto. (2013). Administrasi dan Supervisi Pendidikan. Bandung. Remaja Rosdakarya. Suhertian. (2000). Konsep Dasar dan Teknik Supervisi Pendidikan. Jakarta. Rineka Cipta.

Slametto. (2006). Belajar dan Faktor-Faktor yang mempengaruhi. Jakarta. Erlangga.

Suyadi. (2012). Buku Panduan Guru Frofesional, "penelitian Tindakan Kelas dan Penelitian Tindakan Sekolah.Yogyakarta : Penerbit Andi.

Thaib, Y. (2005). Evaluasi Program. Jakarta. Rineka Cipta. 